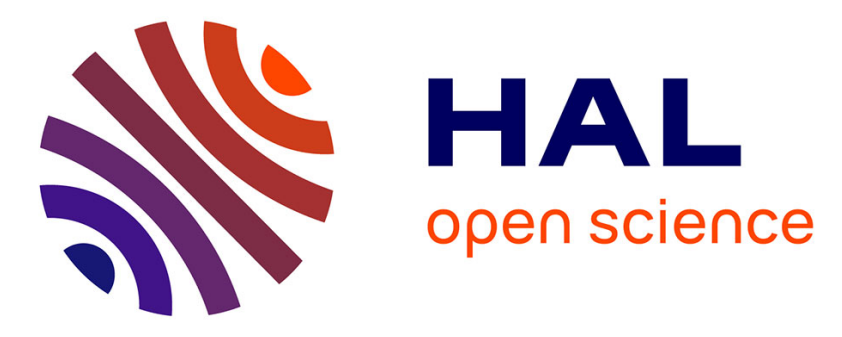

\title{
An original class of small sized molecules as versatile fluorescent probes for cellular imaging
}

Doina Sirbu, Julien Diharce, Ivana Martinić, Nicolas Chopin, Svetlana Eliseeva, Gerald Guillaumet, Stephane Petoud, Pascal Bonnet, Franck Suzenet

\section{- To cite this version:}

Doina Sirbu, Julien Diharce, Ivana Martinić, Nicolas Chopin, Svetlana Eliseeva, et al.. An original class of small sized molecules as versatile fluorescent probes for cellular imaging. Chemical Communications, 2019, 55 (54), pp.7776-7779. 10.1039/C9CC03765A . hal-02373125

\section{HAL Id: hal-02373125 \\ https://hal.science/hal-02373125}

Submitted on 20 Nov 2020

HAL is a multi-disciplinary open access archive for the deposit and dissemination of scientific research documents, whether they are published or not. The documents may come from teaching and research institutions in France or abroad, or from public or private research centers.
L'archive ouverte pluridisciplinaire HAL, est destinée au dépôt et à la diffusion de documents scientifiques de niveau recherche, publiés ou non, émanant des établissements d'enseignement et de recherche français ou étrangers, des laboratoires publics ou privés. 


\section{An Original Class of Small Sized Molecules as Versatile Fluorescent Probes for Cellular Imaging}

Received 00th January 20xx, Accepted 00th January 20xx DOI: $10.1039 / \times 0 \times x 00000 x$
Doina Sirbu, ${ }^{a}$ Julien Diharce, ${ }^{a}$ Ivana Martinić, ${ }^{\mathrm{b}}$ Nicolas Chopin, ${ }^{\mathrm{a}}$ Svetlana V. Eliseeva, ${ }^{\mathrm{b}}$ Gérald

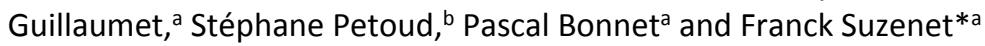

An unusual class, compact in sizes, of fluorescent probes based on pyridazino-1,3a,6a-triazapentalene scaffolds exhibits highly fluorescent properties (quantum yield values up to $73 \%$, large Stokes shifts, emission wavelengths located in the green-yellow range, excellent solubility) with very good photostability suitable for optical imaging applications.

Fluorescent organic molecules are essential compounds for the detection, quantification and understanding of biological processes applied in chemical biology, biochemistry, biomedical research and diagnostics. ${ }^{1}$ The main advantages of fluorescent organic molecules include high versatility, moderate molecular size and weight, chemical stability, and ability to exhibit switchable or activatable spectroscopic properties. This fluorogenic behavior can be initiated by a chemical or biochemical process according to four main different reaction mechanisms: $\mathrm{pH}$ sensitivity, complexation/decomplexation, formation or cleavage of a covalent bond and redox reactions. ${ }^{2-5}$ Although numerous fluorophores have already been described in the literature, the diversity of the molecular frameworks of those commonly used for cell imaging probes is often limited to coumarin, xanthene (fluorescein, rhodamine, Texas), BODIPY and cyanine cores. ${ }^{6,7}$ These dyes cannot be considered as ideal probes for optical imaging since none of them combine high fluorescence with optimal absorption and emission wavelengths, good chemical and photostability, sufficient water solubility and small molecular weight/size.

Therefore, the discovery of novel fluorophore-based scaffolds remains an important challenge to offer new highly versatile platforms providing alternative and/or complementary molecular tools for novel bioimaging applications. ${ }^{8-12}$ In this

a. Institut de Chimie Organique et Analytique - ICOA UMR7311, rue de Chartres, 45100 Orléans, France. E-mail: franck.suzenet@univ-orleans.fr

b. Centre de Biophysique Moléculaire CNRS UPR 4301, rue Charles Sadron, 45071 Orléans Cedex 2, France.

Electronic Supplementary Information (ESI) available: Experimental procedures, characterization data, ${ }^{1} \mathrm{H}$ and ${ }^{13} \mathrm{C}$ NMR spectra, theoretical calculations, spectroscopic analysis, cellular optical imaging, cytotoxicity tests. See DOI: $10.1039 / x 0 x x 00000 x$ context, focusing on very low molecular weight/size fluorophores is of major interest for minimizing pharmacokinetic alterations of the targeting biomolecules to which they are linked. ${ }^{13}$ Small dyes may also find specific interest in ligase fusion proteins. ${ }^{14}$ Obviously, those fluorophores have to rely on (i) optimized spectroscopic properties, including high quantum yield values, large Stokes shifts and good photostability, ${ }^{15,16}$ and (ii) biological media compatibility i.e. good chemical stability, low cytotoxicity, cell permeability and solubility, in order to be considered as suitable probes for cellular imaging. a) Namba et al. :

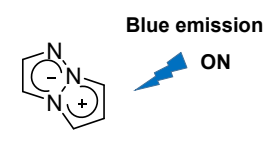

1,3a,6a-triazapentalene (TAP) $\lambda_{\mathrm{em}}=389 \mathrm{~nm} / \phi=0.014$

c) Our work

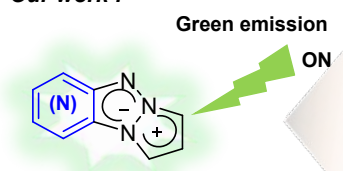

Fused 1,3a,6a-triazapentalenes $\lambda_{\text {em }}$ up to $518 \mathrm{~nm} / \phi$ up to 0.73 b) Hung et al. :

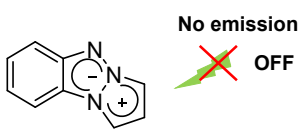

Benzotriazapentalene 1 $\lambda_{\mathrm{em}}=397 \mathrm{~nm} / \phi<0.001$
Fig 1 Summary of the state of the art in the field of triazapentalene derivatives. Photophysical properties of 1a,3a,6a-triazapentalene (a) benzotriazapentalene (b), and novel nitrogen-containing fused ring TAP derivatives (c).

A few years ago, Namba's team pioneered the fluorescent properties of the 1,3a,6a-triazapentalene (TAP) derivatives (Figure $1 \mathrm{a})^{17}$ and showed that this highly condensed dipolar structure offers very promising spectroscopic properties and suitability for biological applications. ${ }^{18,19}$ To study the impact of the TAP substituents on spectroscopic properties, the development of specific synthetic pathways was required. ${ }^{20-26}$ 
Although some improvements of this highly promising TAP scaffold were observed, further investigations towards fused ring chemical entities have not been considered so far as benzotriazapentalene $\mathbf{1}$ as a fused ring system were already reported as non-fluorescent (Figure 1 b). ${ }^{17}$

Herein, we report the design, the synthesis, the fluorescent properties and the cellular imaging compatibility of a novel class of small nitrogen-containing tricyclic frameworks. We demonstrate the crucial impact of the additional fused heteroaromatic ring on the TAP system towards promising spectroscopic properties for such a low molecular weight structure with excellent chemical stability.

In the course of a research program on the design of energetic compounds, we identified pyrazolo-triazolo-pyridine ${ }^{27}$ and pyrazolo-triazolo-pyrazine scaffolds ${ }^{28}$ (Figure 2, compounds 2 and 4 , respectively). We postulated that the electron deficient character of the fused azine or diazine cycle could favor an intramolecular charge transfer (ICT) and promote the emission of this tricyclic scaffold (Figure 1c).

In order to study the effect induced by the presence of nitrogen atoms in the (di)azine rings on the fluorescent properties, we managed to synthesize and characterize the tricyclic scaffolds $\mathbf{1}$, 2, 3 and 4 (Figure 2).

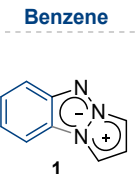

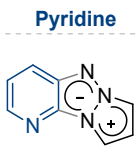

2

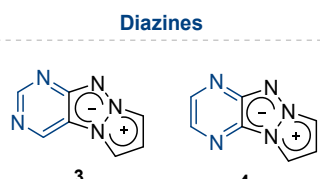

Fig. 2 Chemical structures of compounds 1, 2, 3 and $\mathbf{4}$.

Synthesis of compounds $\mathbf{1},{ }^{29} \mathbf{2}^{27}$ and $\mathbf{4}^{28}$ was undertaken following reported protocols and they were isolated in correct yields (see Supporting Information). Regarding compound 3, an original synthetic pathway was developed in four steps involving a key copper catalyzed C-N bond formation ${ }^{30}$ (see SI for details). Having prepared the triazapentalene scaffolds 1-4, we then carried out the complete spectroscopic characterization (Table 1). The absence of fluorescence for compound 1 was confirmed. ${ }^{17}$ The azine scaffold (compound 2) showed very weak fluorescence in contrast to its diazine isomers (compounds $\mathbf{3}$ and $\mathbf{4}$ ) which exhibited intense fluorescence bands with a very promising quantum yield values of $15 \%$ in DMSO.

Furthermore, the spectroscopic data clearly showed that the number and position of nitrogen atoms in the additional aromatic ring greatly affects the absorption and emission bands positions in agreement with the calculations (SI, Table S1). Interestingly, the presence of an extra nitrogen atom in compound 2 induced $17 \mathrm{~nm}$ and $49 \mathrm{~nm}$ red shifts for absorption and emission bands respectively compared to compound $\mathbf{1}$. This trend is confirmed with a pyrazine-containing fused aromatic ring (compound 4) with a remarkable bathochromic effect for both absorption and emission bands offering a very compact organic fluorescent scaffold with an emission maximum at 516 $\mathrm{nm}$. It should be noted that the position of these two additional nitrogen atoms is particularly relevant as is illustrated with compound $\mathbf{3}$ for which a blue shift of the absorption and emission bands was observed.

Table 1 Spectroscopic characterization of the tricyclic compounds 1, 2, 3 and 4 in DMSO.

\begin{tabular}{cccccc}
\hline Dye & $\begin{array}{c}\lambda_{\text {abs }}[\mathrm{nm}] \\
{[\text { [a] }}\end{array}$ & $\begin{array}{c}\lambda_{\text {em }}[\mathrm{nm}] \\
\text { [b] }\end{array}$ & $\Delta[\mathrm{nm}]^{[\mathrm{c}]}$ & $\varepsilon_{\max }{ }^{[\mathrm{d}]}$ & $\phi^{[\mathrm{e}]}$ \\
\hline $\mathbf{1}$ & 370 & 397 & 27 & 12700 & $<0.001$ \\
$\mathbf{2}$ & 387 & 446 & 59 & 18700 & 0.018 \\
$\mathbf{3}$ & 362 & 440 & 78 & 1200 & 0.15 \\
$\mathbf{4}$ & 418 & 516 & 98 & 15500 & 0.15 \\
\hline
\end{tabular}

[a] Apparent maxima of absorption bands of the dyes. [b] Apparent maxima of emission bands of the dye. [c] Stokes Shift values calculated as the difference between the maxima of absorption and emission bands. [d] Units: L. $\mathrm{mol}^{-1} \cdot \mathrm{cm}^{-1} \cdot[\mathrm{e}] \phi$ is the relative fluorescence quantum yield using Coumarin $153(\phi=0.38$ in EtOH $)$ as a reference standard. ${ }^{31}$

In addition, scaffold $\mathbf{4}$ showed a much higher molar extinction coefficient compared to compound $\mathbf{3}$, giving rise to an improved brightness. The pyrazino-[1a,3a,6a]-triazapentalene 4 stands out as our model scaffold which could be easily optimized by a simple and large scope of chemical modulation.

Interestingly, the fluorescent tricyclic scaffold $\mathbf{4}$ displayed a good solubility in water $\left(>1 \mathrm{mg} \cdot \mathrm{mL}^{-1}\right)$ along with an apparent position of the emission maximum larger than $530 \mathrm{~nm}$, a Stokes shift of approximately $130 \mathrm{~nm}$ and a molar extinction coefficient of higher than $12000 \mathrm{M}^{-1} \cdot \mathrm{cm}^{-1}$. The excellent chemical stability of dye 4 was also observed from $\mathrm{pH} 4$ to $\mathrm{pH} 11$ in water solutions. The solvatochromic behavior of $\mathbf{4}$ was obtained by recording absorption and emission spectra in various solvents. Whereas almost no change in the positions of the apparent absorption maxima was observed, a strong bathochromic effect was noticed from apolar to protic polar solvents characterized by a larger Stokes shift in water (128 nm) compared to chloroform $(85 \mathrm{~nm})$ (see SI for details).

In order to provide gain insights into the effect of nitrogen additions on the (het)aryl part of the tricyclic molecules (1 to 4), TD-DFT calculations were carried out ${ }^{10,32}$ (see SI for details) and analysis of frontier orbitals for each compound was performed. The electronic density of the HOMO appeared, in general, to be weakly impacted by the substitution of a carbon atom by a nitrogen. The presence of nitrogen on the fused ring decreased the HOMO electronic density on adjacent atoms without any impact on the 1,3a,6a-triazapentalene moiety. In contrast, the pyridine ring in $\mathbf{2}$ displaced the LUMO electronic density from the 1,3a,6a-triazapentalene moiety to the 6-member ring, increasing the positive partial charges at the carbons and the $\pi$ deficient character of the fused ring (see Figure 3 and Table S1). These two complementary effects may explain the enhancement of the intramolecular charge transfer (ICT).
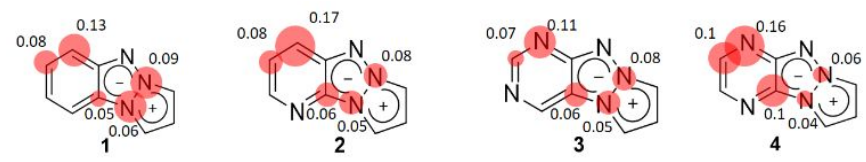

Figure 3. Major atomic contribution to the LUMO density for compounds 1 to 4 . 
The pyrazine ring in $\mathbf{4}$ slightly emphasized the effect on the LUMO atomic contribution compared to 1 while the pyrimidine ring in $\mathbf{3}$ did not induce the same behavior. Indeed, by comparing $\mathbf{3}$ and $\mathbf{4}$, the LUMO density is less localized on the pyrimidine part than on the pyrazine. Consequently, the enhanced $\pi$-electron deficient character of the pyrazine could Scheme 2 Synthesis of various diversified pyrazinyl-1a,3a,6a-triazapentalenes
from chloropyrazine $\mathbf{5}$ (pathway A) and from organometallic coupling processes with halogeno-triazapentalene $\mathbf{4 i}$ or $\mathbf{4 j}$ (pathway B).

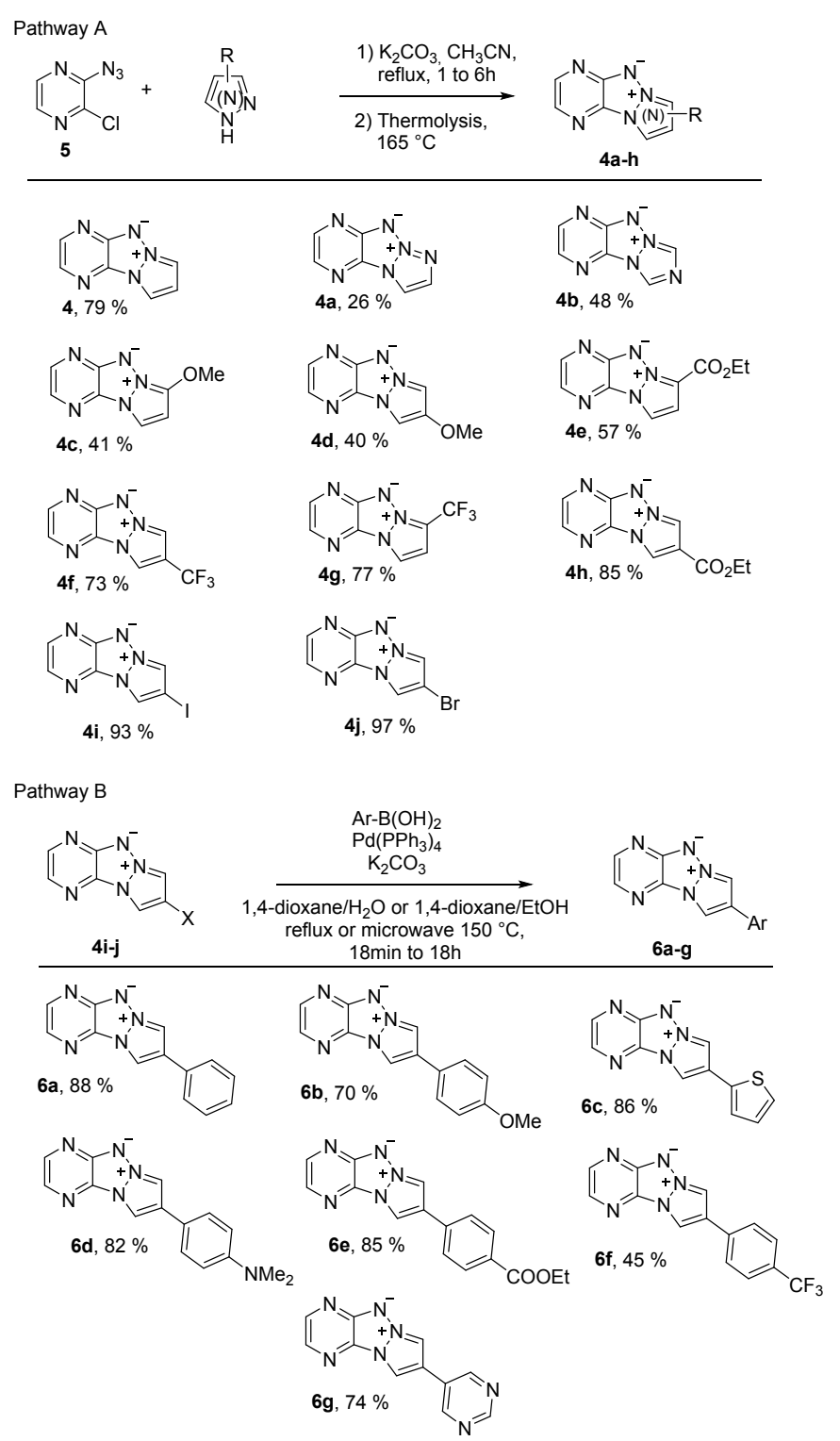

explain the better fluorescence properties observed for compound 4.

With this information in hand, the potential of this new family of fluorophores was further investigated by considering the influence of an extra nitrogen in the azole ring as well as the effect of substituents on the reactivity and fluorescence properties. Various tetrazapentalenes and triazapentalenes bearing donor or acceptor groups on the azole moiety were synthesized in moderate to excellent yields in accordance with synthetic pathway A. In addition, aryl substituted triazapentalenes were obtained through a Suzuki cross-coupling reaction following pathway $B$ (Scheme 2 , see SI for details).

Table 2. Spectroscopic characterization of tricyclic analogs of (pyrazinyl)-1a,3a,6atriazapentalene and -tetrazapentalene in $\mathrm{CH}_{2} \mathrm{Cl}_{2}$ and DMSO.

\begin{tabular}{|c|c|c|c|c|c|}
\hline Dye & Solvent & $\begin{array}{c}\lambda_{\text {abs }}[\mathrm{nm}] \\
{[\mathrm{a}]}\end{array}$ & $\begin{array}{c}\lambda_{\mathrm{em}}[\mathrm{nm}] \\
{[\mathrm{b}]}\end{array}$ & $\varepsilon_{\max }[\mathrm{c}]$ & $\phi[d]$ \\
\hline 4 & $\mathrm{CH}_{2} \mathrm{Cl}_{2}$ & 415 & 494 & 13000 & 0.42 \\
\hline $4 a$ & $\mathrm{CH}_{2} \mathrm{Cl}_{2}$ & 391 & 427 & 12700 & 0.51 \\
\hline $4 b$ & $\mathrm{CH}_{2} \mathrm{Cl}_{2}$ & 410 & 470 & 12133 & 0.37 \\
\hline $4 c$ & DMSO & 436 & 529 & 13200 & 0.03 \\
\hline \multirow{2}{*}{$4 d$} & $\mathrm{CH}_{2} \mathrm{Cl}_{2}$ & 410 & 512 & 7105 & 0.08 \\
\hline & DMSO & 415 & 521 & 13700 & 0.03 \\
\hline $4 e$ & $\mathrm{CH}_{2} \mathrm{Cl}_{2}$ & 416 & 473 & 24157 & 0.023 \\
\hline $4 f$ & $\mathrm{CH}_{2} \mathrm{Cl}_{2}$ & 409 & 467 & 14911 & 0.52 \\
\hline $4 g$ & $\mathrm{CH}_{2} \mathrm{Cl}_{2}$ & 403 & 464 & 14706 & 0.034 \\
\hline $4 h$ & $\mathrm{CH}_{2} \mathrm{Cl}_{2}$ & 418 & 473 & 11470 & 0.73 \\
\hline $4 i$ & $\mathrm{CH}_{2} \mathrm{Cl}_{2}$ & 414 & 483 & 16443 & 0.27 \\
\hline $4 j$ & $\mathrm{CH}_{2} \mathrm{Cl}_{2}$ & 412 & 487 & 19300 & 0.27 \\
\hline $6 a$ & $\mathrm{CH}_{2} \mathrm{Cl}_{2}$ & 418 & 496 & 13781 & 0.45 \\
\hline $6 b$ & $\mathrm{CH}_{2} \mathrm{Cl}_{2}$ & 417 & 497 & 18185 & 0.29 \\
\hline $6 c$ & $\mathrm{CH}_{2} \mathrm{Cl}_{2}$ & 417 & 491 & 15085 & 0.38 \\
\hline $6 d$ & $\mathrm{CH}_{2} \mathrm{Cl}_{2}$ & 406 & 518 & 16151 & 0.04 \\
\hline $6 e$ & $\mathrm{CH}_{2} \mathrm{Cl}_{2}$ & 419 & 485 & 14200 & 0.48 \\
\hline $6 f$ & $\mathrm{CH}_{2} \mathrm{Cl}_{2}$ & 418 & 484 & 14711 & 0.52 \\
\hline $6 \mathrm{~g}$ & $\mathrm{CH}_{2} \mathrm{Cl}_{2}$ & 418 & 477 & 11500 & 0.51 \\
\hline
\end{tabular}

[a] Apparent maxima of absorption bands. [b] Apparent maxima of emission band. [c] Units: L. $\mathrm{mol}^{-1} \cdot \mathrm{cm}^{-1}$. [d] $\phi$ is the relative fluorescence quantum yield estimated by using Coumarin $153(\phi=0.38 \mathrm{in} \mathrm{EtOH})$ as a reference standard. ${ }^{31}$

As shown in Table 2, the presence of an extra nitrogen on the azole ring (for compounds $\mathbf{4 a}$ and $\mathbf{4 b}$ ) produced a strong hypochromic effect without affecting the other spectroscopic properties $(\varphi$ and $\varepsilon)$. In contrast, an electron donating group wherever the position (compounds $\mathbf{4 c}, \mathbf{4 d}$ and $\mathbf{6 d}$ ) produced a bathochromic effect, while being detrimental for the quantum yield. However, an electron-withdrawing group $\left(\mathrm{CF}_{3}, \mathrm{CO}_{2} \mathrm{Et}\right.$, $\mathrm{ArCF}_{3}$ and $\mathrm{ArCO}_{2} \mathrm{Et}$ for compounds $\mathbf{4 f}, \mathbf{4 h}, \mathbf{6 f}$ and $\mathbf{6 e}$ respectively) was highly beneficial to the quantum yield (up to $73 \%$ in $\mathrm{CH}_{2} \mathrm{Cl}_{2}$ for compound $\mathbf{4 h}$ ) when attached in position 3 of the azole. The molar extinction coefficient was greatly improved when the ester group was introduced in position 2. Finally, it is noteworthy that excitation and emission wavelengths were almost unaffected by the presence of an aryl group on the azole moiety (6a vs 4 ).

In order to demonstrate the ability of the novel triazapentalene compounds to be used as fluorescence probes for the imaging of living cells, epifluorescence microscopy experiments were performed on HeLa cells incubated with dye $6 \mathbf{e}$. The resulting images suggest that this dye can be taken up by cells and the signal in the green region of the visible spectrum was recorded upon excitation using a $414 \mathrm{~nm}$ band pass $46 \mathrm{~nm}$ filter (see SI, Figure S9, Top) whereas, a minimal autofluorescence signal was observed for untreated cells (see SI, Figure S9, Bottom).

Considering the very good quality of the signal in cells, the photostability of dye $6 \mathrm{e}$ was evaluated and compared to a commercially available bodipy fluorophore, LysoTracker Green DND-26. Interestingly, compound 6 e shows a very good 
photostability (Figure 4) with a remaining signal up to $480 \mathrm{~s}$ (see SI for details). In this context, the cytotoxicity of probe 6 e was evaluated with the Alamar Blue assay and more than $95 \%$ of cell viability was observed up to $170 \mu \mathrm{M}$ concentration (see SI for details).

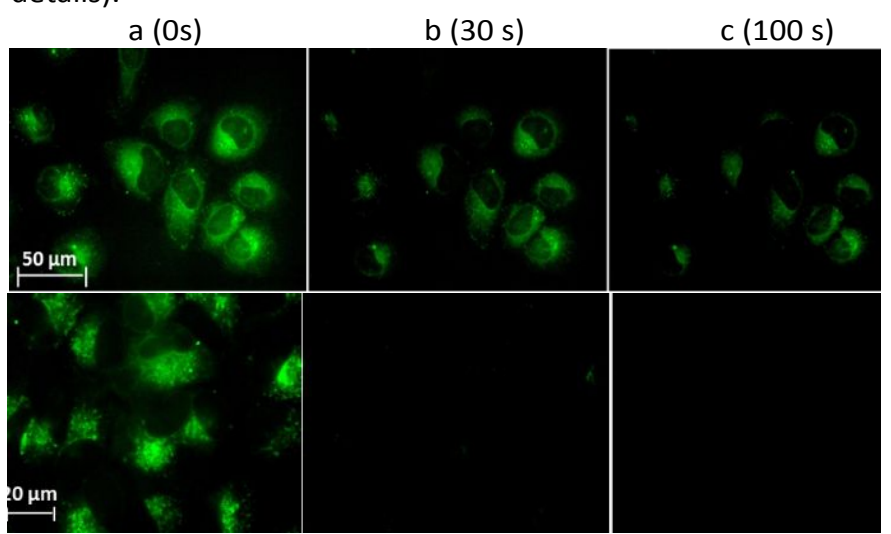

Fig 4 Photobleaching experiments (epifluorescence microscopy) performed on HeLa cells incubated during $1 \mathrm{~h} 30$ min with a $95 \mu \mathrm{M}$ solution of compound $6 \mathrm{e}$ (top) or with $50 \mathrm{nM}$ LysoTracker Green DND-26 (bottom) after exposure to the continuous excitation light at $414 \mathrm{~nm}$, band pass $46 \mathrm{~nm}$ filter during different times: (a) $0 \mathrm{~s}$, (b) $30 \mathrm{~s}$, (c) $100 \mathrm{~s} .63 \times$ objective.

\section{Conclusions}

We created an original versatile tricyclic scaffold offering highly promising fluorescent properties. The fused diazine on the triazapentalene ring induced a strong bathochromic shift of the emission bands combined with improved quantum yield values due to a probable ICT process. This family appears to be nontoxic, highly photostable, chemically stable and some compounds are amphiphilic. With epifluorescence microscopy experiments we demonstrated that compound $\mathbf{6 e}$ can serve as a fluorescent probe for the optical imaging of living cells. A combination of small size/low molecular weight, good photostability, enhanced photophysical properties, large Stokes shifts, and versatility makes the reported fused triazapentalene family of fluorophores a promising tool for biological applications and is currently being explored for optical imaging.

\section{Conflicts of interest}

There are no conflicts to declare.

\section{Acknowledgment}

We thank the master students- Emeline Cristofaro and Dorian Guillot, for preliminary theoretical calculations of some compounds. This work was supported by the French ministry of research (D.S.), Labex SynOrg (ANR-11-LABX-0029), Labex IRON (ANR-11-LABX-0018-01), University of Orléans and Région Centre Val de Loire. S.P. acknowledges support from Institut National de la Santé et de la Recherche Médicale (INSERM). In addition, this work is partially supported by la Ligue Contre le Cancer, La Région Centre and the Réseau Canaux Ioniques du Cancéropôle Grand Ouest.

\section{Notes and references}

1 M. F. Juette, D. S. Terry, M. R. Wasserman, Z. Zhou, R. B. Altman, Q. Zheng and S.C Blanchard, Curr. Opin. Chem. Biol. 2014, 20, 103.

2 X. Li, X. Gao, W. Shi and H. Ma, Chem. Rev., 2014, 114, 590.

3 H. Zhu, J. Fan, J. Du and X. Peng, Acc. Chem. Res., 2016, 49, 2115.

4 Y. Niko, P. Didier, Y. Mely, G.-I Konishi and A. S. Klymchenko, Scientific Reports, 2016, 6, 18870.

5 A. S. Klymchenko, Acc. Chem. Res., 2017, 50, 366.

6 L. D., Lavis and R. T. Raines, ACS Chem. Biol. 2008, 3, 142.

7 L. D.,Lavis and R. T. Raines, ACS Chem. Biol. 2014, 9, 855.

8 E. Kim, M. Koh, J. Ryu and S. B. Park, J. Am. Chem. Soc. 2008 130, 12206.

9 E. J. Choi, E. Kim, Y. Lee, A. Jo and S. Bum Park, Angew. Chem. Int. Ed., 2014, 53, 1346.

10 Y. Cheng, G. Li, Y. Liu, Y. Shi, G. Gao, D. Wu, J. Lan and J. You, J. Am. Chem. Soc. 2016, 138, 4730.

11 E. Heyer, P. Lory, J. Leprince, M. Moreau, A. Romieu, M. Guardigli, A. Roda and R. Ziessel, Angew. Chem. Int. Ed., 2015, 54, 2995.

12 B. M. White, Y. Zhao, T. E. Kawashima, B. P. Branchaud, M. D. Pluth and R. Jasti, ACS Cent. Sci., 2018, 1173.

13 H. Kobayashi, M. Ogawa, R. Alford, P. L. Choyke and Y. Urano, Chem. Rev., 2010, 110, 2620.

14 Luke D. Lavis, Biochemistry, 2017, 56, 5165.

15 Q. Zheng, M. F. Juette, S. Jockusch, M. R. Wasserman, Z. Zhou, R. B. Altmana and S. C. Blanchard, Chem. Soc. Rev., 2014, 43,1044.

16 Z. Liu, L. D. Lavis and E. Betzig, Mol. Cell, 2015, 58, 644.

17 K. Namba, A. Osawa, S. Ishizaka, N. Kitamura and K. Tanino, J. Am. Chem. Soc., 2011, 133, 11466.

18 R. Kamada, F. Tano, F. Kudoh, N. Kimura, Y. Chuman, A. Osawa, K. Namba, K. Tanino and K. Sakaguchi, PLOS ONE, 2016, 11(8): e016062.

19 J.-I. Sawada, A. Osawa, T. Takeuchi, M. Kaneda, S. Oishi, N. Fujii, A. Asai, K. Tanino and K. Namba, Bioorg. Med. Chem. Lett., 2016, 26, 5765.

20 K. Namba, A. Mera, A. Osawa, E. Sakuda, N. Kitamura and K. Tanino, Org. Lett., 2012, 14, 5554.

21 R. Cai, D. Wang, Y. Chen, W. Yan, N. R. Geise, S. Sharma, H. Li, J. L. Petersen, M. Li and X. Shi, Chem. Commun., 2014, 50, 7303.

22 K. Namba, A. Osawa, A. Nakayama, A. Mera, F. Tano, Y. Chuman, E. Sakuda, T. Taketsugu, K. Sakaguchi, N. Kitamura and K. Tanino, Chem. Sci., 2015, 6, 1083.

23 A. Nakayama, S. Nishio, A Otani, A. Mera, A. Osawa, K. Tanino and K. Namba, Chem. Pharm. Bull., 2016, 64, 830

24 A. Mera, M. Ito, A. Nakayama and K. Namba, Chem. Lett., 2017, 46, 539.

25 T. Hayashi, A. Osawa, T. Watanabe, Y. Murata, A. Nakayama and K. Namba, Tetrahedron Lett., 2017, 58, 1961.

26 B. Verbelen and W. Dehaen, Org.Lett. 2016, 18, 6412.

27 C. Nyffenegger, E. Pasquinet, F. Suzenet, D. Poullain, C. Jarry,J.-M. Léger and G. Guillaumet, Tetrahedron, 2008, 64, 9567.

28 C. Nyffenegger, E. Pasquinet, F. Suzenet, D. Poullain and G. Guillaumet, Synlett, 2009, 1318.

29 B. M. Lynch and Y.-Y. Hung, J. Heterocycl. Chem., 1965, 2, 218.

30 H.-J. Cristau, P. P. Cellier, J.-F. Spindler and M. Taillefer, Eur. J. Org. Chem., 2004, 695.

31 M. Brouwer and A. M. Brouwer, Pure Appl. Chem., 2011, 83, 2213.

32 D. Jacquemin, B. Mennucci and C. Adamo, Phys. Chem. Chem. Phys., 2011, 13, 16987. 